but this remains high. As women pose the greater diagnostic problem we now perform laparoscopy in all of them before appendicectomy. We hope that this will reduce the number of unnecessary operations further.

The rate of complications after removal of a normal appendix is $17 \%$, which is much higher than that after a diagnostic laparoscopy (3\%). ${ }^{3}$ Laparoscopy and other diagnostic aids including computers ${ }^{4}$ and peritoneal aspiration cytology ${ }^{5}$ provide the opportunity to reduce the high rate of unnecessary appendicectomies.

1 Chang FC, Hogle HH, Welling DR. The fate of the negative appendix. Am f Surg 1973;126:752-4

2 Leape LL, Ramenofsky ML. Laparoscopy for questionable appendicitis-can it reduce the Leape LL, Ramenofsky ML. Laparoscopy for questiona
negative appendicectomy rate? Ann Surg 1980;191:410-3.

3 Chamberlain G, Brown JC. The report of the working party of the confidential enquiry into gynaecological laparoscopy. London: Royal College of Obstetricians and Gynaecologists, 1978.

4 Adams ID, Chan M, Clifford PC, et al. Computer aided diagnosis of acute abdominal pain: a multicentre study. BrMed $\mathcal{F}$ 1986;293:800-4.

5 Stewart RJ, Gupta RK, Purdie GL, Isbister WH. Fine-catheter aspiration cytology of peritoneal cavity improves decision-making about difficult cases of acute abdominal pain. Lancet 1986;ii:1414-5.

(Accepted 26 fanuary 1988)

Academic Surgical Unit, St Mary's Hospital, London W2 1NY

S PATERSON-BROWN, FRCSED, clinical research fellow

J N THOMPSON, MA, FRCS, lecturer in surgery

J R T ECKERSLEY, FRCS, clinical research fellow

G A PONTING, FRCS, surgical registrar

H A F DUDLEY, CHM, FRCSED, professor of surgery

Correspondence to: Mr Paterson-Brown.

\section{Does cardioversion of atrial fibrillation result in myocardial damage?}

There is concern that cardioversion of atrial fibrillation to sinus rhythm may damage the heart.' To investigate this possibility we examined patients undergoing elective cardioversion. Creatine kinase and its more specific $\mathrm{MB}$ isoenzyme cannot be relied on as markers of myocardial damage because of technical limitations in their measurement; thus we used technetium-99m stannous pyrophosphate, a sensitive and specific marker of myocardial damage, as an additional procedure. ${ }^{2}$

\section{Patients, methods, and results}

We examined 25 patients aged 33-78 (mean 55.9). All were treated with anticoagulant drugs before and for six weeks after cardioversion to prevent thromboembolic complications. Samples of plasma were obtained before cardioversion and every six hours thereafter for 36 hours and assayed for activity of total creatine kinase and its MB isoenzyme. ${ }^{99 \mathrm{~m} T C}$ stannous pyrophosphate scanning was performed before and 36 hours after cardioversion, planar views and tomographic scans being obtained. Twenty one of the patients were converted to sinus rhythm; 16 of these 21 remained in sinus rhythm at follow up three months to two years later.

The scans did not show any myocardial uptake, but uptake was seen in the anterior chest wall in five of six patients who had received a high energy shock $(400 \mathrm{~J})$. Baseline activity of creatine kinase ranged from 8 to $176 \mathrm{U} / 1$ (mean $36 \mathrm{U} / \mathrm{l}$ ), normal range $<75 \mathrm{U} / \mathrm{l}$ ), and baseline activity of the $\mathrm{MB}$ isoenzyme was below the upper limit of the normal range in all patients. Peak activity of creatine kinase ranged from 17 to $8586 \mathrm{U} / \mathrm{l}$ (mean $917 \mathrm{U} / \mathrm{l}$ ); peak activity of the MB isoenzyme was increased in six patients but appreciably so in only two (at 34 and $102 \mathrm{U} / \mathrm{l})$, in whom peak activity of total creatine kinase was high (1810-8586 U/I respectively).

\section{Comment}

Experiments on animals have shown myocardial damage secondary to defibrillation. ${ }^{3}$ In humans, although activity of various enzymes related to cardiac function has been shown to increase after cardioversion, that of the more specific MB isoenzyme of creatine kinase has not. ${ }^{1}$ Several problems arise in interpreting $M B$ isoenzyme activity. Firstly, the reference range applies to ambulant patients without chest trauma. Secondly, in electrophoresis the error of measurement of activity of the MB isoenzyme increases as total creatine kinase activity and the percentage of $\mathrm{MB}$

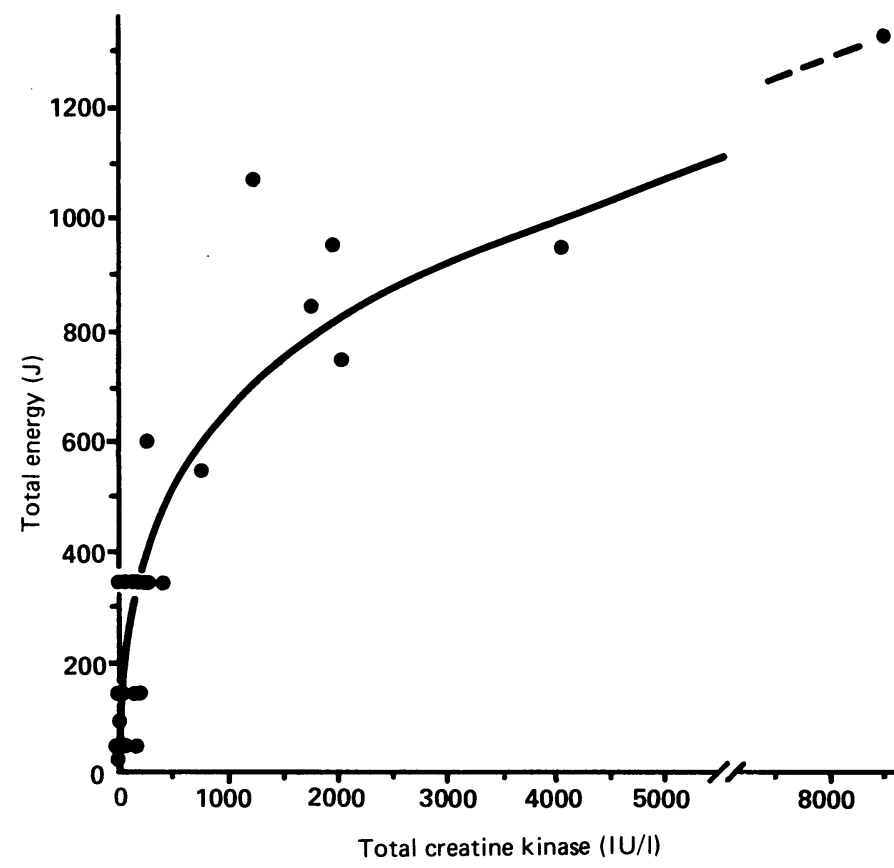

Total peak creatine kinase and cumulative energy used.

isoenzyme decrease. ${ }^{4}$ This probably explains why in four patients there was a slight increase in peak activity of MB isoenzyme associated with a moderate increase in total creatine kinase activity; although this may have indicated slight myocardial damage, this is unlikely.

A third problem is that the $\mathrm{MB}$ isoenzyme of creatine kinase is not specific for myocardial damage. Skeletal muscle contains 3-5\% of this isoenzyme and myocardial muscle $14-20 \% .^{5}$ Two patients had fairly high peak activity of MB isoenzyme associated with a substantial rise in total creatine kinase activity, most probably as a result of damage to skeletal muscle due to the high energies used. This is substantiated by the fact that in both patients uptake of ${ }^{99 \mathrm{~m}}$ Tc stannous pyrophosphate was seen in the chest wall but not the myocardium. ${ }^{9 m} \mathrm{Tc}$ stannous pyrophosphate scanning, especially when tomographic imaging is used, clearly distinguishes myocardial damage from damage to the chest wall. A release of over $100 \mathrm{U} / 1$ of the $\mathrm{MB}$ isoenzyme of creatine kinase represents necrosis of over $1 \mathrm{~g}$ of myocardial tissue and should be well within the imaging threshold of the scans. Slight chest discomfort in those patients with soft tissue damage was the only side effect noted.

As we did not find any conclusive evidence of myocardial damage we conclude that patients with atrial fibrillation should be considered for cardioversion.

1 Ehsani A, Ewy GA, Sobel BE. Effects of electrical countershock on serum creatine phosphokinas (CPK) isoenzyme activity. Am $\mathcal{F}$ Cardiol 1976;37:12-8.

2 Coleman R, Klein MS, Roberts R, Sobel BE. Improved detection of myocardial infarction with technetium-99m stannous pyrophosphate and serum MB creatine phosphokinase. Am f Cardio 1976;37:732-5.

3 Doherty PW, McLaughlin PR, Billingham M, Kernoff R, Goris ML, Harrison DC. Cardiac damage produced by direct current countershock applied to the heart. Am $\mathcal{F}$ Cardiol 1978;43: 225-8.

4 Griffiths PD. CK-MB: a valuable test? Ann Clin Biochem 1986;23:238-42.

5 Seigel AJ, Lawrence M, Silverman P, Holman L. Elevated creatine kinase $M B$ isoenzyme levels in marathon runners. FAMA 1981;246:2049-51.

(Accepted 23 December 1987)

Aberdeen Royal Infirmary, Aberdeen AB2 9ZB

$M$ J METCALFE, MRCP, clinical research fellow, department of cardiology

F SMITH, MD, FFR, consultant radiologist

K JENNINGS, FRCP, consultant cardiologist

Department of Chemical Pathology, University of Aberdeen, Aberdeen AB9 1FX

N PATERSON, BSC, PHD, senior lecturer

Correspondence to: Dr Metcalfe. 